\title{
EBV-Related Sarcoma
}

National Cancer Institute

\section{Source}

National Cancer Institute. EBV-Related Sarcoma. NCI Thesaurus. Code C162305.

Sarcoma that is caused by Epstein-Barr virus infection. 